\title{
Is the Disease Burden from COPD in Norway Falling off? A Study of Time Trends in Three Different Data Sources
}

This article was published in the following Dove Press journal: International Journal of Chronic Obstructive Pulmonary Disease

\author{
Hasse Melbye (D) \\ Jon Helgeland (1D ${ }^{2}$ \\ $\varnothing y s t e i n$ Karlstad $\mathbb{D}^{3}$ \\ Inger Ariansen $\mathbb{D}^{3}$ \\ Arnulf Langhammer $\mathbb{1 D}^{4}$ \\ Torbjørn Wisløff $\mathbb{D}^{\prime}$ \\ Per Nafstad (1D ${ }^{3}$ \\ Wenche Nystad ${ }^{3}$ \\ 'General Practice Research Unit, \\ Department of Community Medicine, \\ UIT the Arctic University of Norway, \\ Tromsø, Norway; ${ }^{2}$ Norwegian Institute \\ of Public Health, Division of Health \\ Services, Oslo, Norway; ${ }^{3}$ Norwegian \\ Institute of Public Health, Department of \\ Non-Communicable Diseases, Oslo, \\ Norway; ${ }^{4}$ Department of Public Health \\ and Nursing, Faculty of Medicine and \\ Health Sciences, NTNU, Norwegian \\ University of Science and Technology, \\ Trondheim, Norway
}

Correspondence: Hasse Melbye General Practice Research Unit, Department of Community Medicine, UIT the Arctic University of Norway, Tromsø 9037, Norway

Tel +47952I3200

Email hasse.melbye@uit.no
Background: Less smoking should lead to fewer COPD cases. We aimed at estimating time trends in the prevalence and burden of COPD in Norway from 2001 to 2017.

Methods: We used pre-bronchodilator spirometry and other health data from persons aged 40-84 years in three surveys of the Tromsø Study, 2001-2002, 2007-2008 and 2015-2016. We applied spirometry lower limits of normal (LLN) according to Global Lung Initiative 2012. Agestandardized prevalence was determined. We defined COPD as $\mathrm{FEV}_{1} / \mathrm{FVC}<\mathrm{LLN}$ in subjects reporting dyspnea or coughing, and moderate to severe COPD when $\mathrm{FEV}_{1}<\mathrm{LLN}$ was found in addition. We identified hospitalizations due to COPD exacerbations in the Norwegian Patient Registry 2010-2017, and retrieved the use of COPD medication from the Norwegian Prescription Database. Change in prevalence was analyzed by logistic regression.

Results: In the Troms $\varnothing$ Study, the age-standardized prevalence of daily smoking dropped from $29.9 \%$ to $14.1 \%$ among women and from $31.4 \%$ to $12.8 \%$ among men $(P<0.0001)$. The agestandardized prevalence of COPD dropped from $7.6 \%$ to $5.6 \%$ among women $(P=0.2)$ and from $7.3 \%$ to $5.6 \%$ among men $(P=0.003)$ and of moderate to severe COPD from $5.2 \%$ to $2.7 \%$ among women $(P=0.0003)$ and from $4.6 \%$ to $3.2 \%$ among men $(P=0.0008)$. Among men, the yearly age-standardized prevalence of hospitalization due to COPD exacerbation decreased from 3.6 to 3.0 per 1000 inhabitants aged $40-84$ years $(P<0.0001)$. Correspondingly, dispensing oral corticosteroids or/and antibiotics for COPD exacerbations dropped from 6.6 to 5.8 per 1000 $(P<0.0001)$, while dispensing maintenance treatment increased $(P<0.0001)$.

Conclusion: COPD morbidity decreased between 2001 and 2017, which might partly be due to less smoking. The drop in smoking prevalence gives promise of a further substantial decrease in the coming decades.

Keywords: smoking, COPD, epidemiology, general population

\section{Background}

The prevalence of smoking in western countries is reversing, ${ }^{1}$ and between 2001 and 2017 the prevalence of daily smoking in Norway among adults dropped from $30 \%$ to $11 \%{ }^{2}$ Due to this, one may expect that the prevalence of COPD also will decrease. ${ }^{3}$ Some European studies have shown reductions in COPD prevalence during the last decades, ${ }^{4-7}$ and a Global Burden of Disease Study from 2015 suggested a decreased age-adjusted prevalence of COPD in 195 countries. $^{8}$ A corresponding reduction in hospitalizations due to COPD was not found in Portugal between 2000 and 2010, and in China, the hospitalization rate due to COPD increased between 2005 and $2015,{ }^{10}$ despite a stable prevalence of smoking. 
The aim of the present study was to estimate time trends in the prevalence and burden of COPD by using three different sources of data from 2001 to 2017.

\section{Methods}

First, we used three regional repeated population based health surveys of the Tromsø Study, the 5th, 6th, and 7th, accomplished in 2001-2, 2007-8 and 2015-16. Furthermore, we used two Norwegian mandatory registers: The Norwegian Patient Registry (NPR), that provides individual-level information from all hospitalizations and outpatient visits to the specialized health services, and the Norwegian Prescription Database (NorPD), which provides individual-level information on all prescription drugs dispensed from pharmacies to patients in ambulatory care in Norway since 2004.

The Tromsø Study contributes with data on smoking, self-reported COPD and spirometry in participants aged 40-84 years. The same range of age has also been applied to the NPR which contributes with data on hospitalizations for COPD from 2010 to 2017 and the NorPD which contribute with individual prescriptions on COPD medicines between 2010 and 2017.

\section{The Tromsø Study}

The Tromsø Study is a repeated health survey of the population of Troms $\varnothing,{ }^{11}$ a university city in the northern part of Norway with 75.000 inhabitants. A random sample of the Tromsø population was invited to baseline questionnaires and clinical measurements in the 5th and 6th surveys, whereas all inhabitants of Tromsø aged 40 years or more were invited to the 7th survey (2015-16). Random samples stratified by age were invited to extended examinations, including spirometry. In addition, participants who had taken part in extended examinations in the 4th survey (1994) were also invited. These had also been randomly selected based on age. ${ }^{11}$

All surveys were approved by the Regional Committee for Medical and Health Research Ethics. All study participants gave written consent.

\section{Questionnaires}

Tromsø 5-7 included similar questionnaires on smoking habits, diseases, and symptoms. In Tromsø 5 (2001) the participants were asked "do you have or have you had chronic bronchitis/emphysema". In Tromsø 6 and 7, the question was worded "do you have or have you had chronic bronchitis/emphysema/COPD". A positive answer to this question was regarded as self-reported COPD. At all three surveys a similar question was answered on asthma: "do you have or have you had asthma". Questions on respiratory symptoms were in each survey taken from the MRC questionnaire of 1986: "Do you get short of breath when hurrying on level ground or walking up a slight hill", and "Do you cough about daily in periods of the year". ("in the winter" in the MRC questionnaire was changed to "in periods of the year" to fit the Norwegian climate). A positive answer to one of these questions was used when defining COPD, in line with recommendation from Global Initiative for Chronic Obstructive Lung Disease (GOLD). ${ }^{12}$ The participants were asked if the cough was productive and: "If you cough about daily for some periods of the year, have you had this kind of cough for as long as 3 months in each of the last two years".

\section{Examinations}

Height and weight were measured standing, wearing light clothing and without shoes. Spirometry was carried out according to the standards of the American Thoracic Society/European Respiratory Society. ${ }^{13,14}$ The spirometers used were SensorMedics Vmax Legacy in Tromsø 5 and SensorMedics Vmax Encore in Tromsø 6 and 7. (VIASYS Healthcare Respiratory Technologies, Yorba Linda, CA, USA). Calibration was performed every morning. Cross calibration studies have shown that the Vmax Legacy underestimated forced expiratory volume after one second $\left(\mathrm{FEV}_{1}\right)$ and forced vital capacity (FVC), and correction factors were estimated as $+2.5 \%$ for $\mathrm{FEV}_{1}$ and $+5.2 \%$ for FVC. ${ }^{15}$ The results were discarded if the $\mathrm{FEV}_{1}$ was $<0.3 \mathrm{~L}$ or if expiration lasted for less than $3 \mathrm{~s}$ (FVC $\leq \mathrm{FEV}_{3}$ ). The Global Lung Initiative (GLI) 2012 reference values were used. ${ }^{16}$ At each survey, three to six trained technicians shared the conduction of the spirometry. As a measure of test quality, the duration of the expiration was estimated by calculating the mean difference between FVC and Forced expiratory volume after $6 \mathrm{~s}\left(\mathrm{FEV}_{6}\right)$. Postbronchodilator spirometry was not carried out. The participants were not asked to discontinue their usual medication the examination day.

Oxygen saturation $\left(\mathrm{Sp}_{2}\right)$ was examined after resting for 15 mins with a pulse oximeter Onyx II model 9550 (Nonin Medical, Inc., Plymouth, MN, USA). The highest value after three measurements was registered. $\mathrm{SpO} 2$ values $\leq 95 \%$ were regarded below normal. ${ }^{17}$ We only accepted $\mathrm{Sp}_{2}$ values $\geq 80 \%$, due to uncertainties linked to lower values. 


\section{Hospitalization for COPD}

The Norwegian Patient Registry (NPR) contributed with data on hospitalization for COPD from 2010 to 2017. Among all department admissions to hospitals reported to the NPR for day or inpatient care, admissions for COPD were included if non-elective, the patient was less than 85 and at least 40 years old, and either the patient died in hospital or length of stay was at least $24 \mathrm{hrs}$. NPR uses the Norwegian version of ICD-10 for diagnostic coding. The diagnosis criterion for COPD admission was either a main diagnosis of COPD (J40.X-J44.X), or a main diagnosis of dyspnoea (R06.0), influenza (J09.X-J11.X), pneumonia (J12.X-J18.X), acute bronchitis (J20.x), lower respiratory infection (J22.x), acute, severe asthma (J46.x) or respiratory failure (J96.x), together with a secondary diagnosis of COPD. Subsequent department admissions, at the same or a different hospital, separated by no more than $8 \mathrm{hrs}$, were merged. Only the first admission per patient per calendar year was included in the analysis, which was needed for the calculation of prevalence. The Norwegian Directorate of Health gave permission to use data from NPR.

\section{Use of COPD Medication}

The Norwegian Prescription Database (NorPD) contributed with data on the use of COPD medication from 2010 to 2017. NorPD contains patient-level data on all prescription drugs dispensed from pharmacies in Norway to patients in ambulatory care since 2004. We counted the number of patients receiving drugs at least once from each of three types of drug treatment for COPD (maintenance treatment, short-acting symptomatic treatment only, and exacerbation treatment) per calendar year during 2008-2017. All drugs in NorPD are classified according to the Anatomical Therapeutic Chemical (ATC) classification system. We defined pharmacological maintenance treatment of COPD as patients who received long-acting $\beta 2$ agonists (LABA; ATC codes R03AC12, 13, 18 and 19); long-acting muscarinic antagonists (LAMA; R03BB); long-acting $\beta 2$ agonists as fixed combination with inhaled corticosteroids or long-acting muscarinic antagonists (R03AK, R03AL); theophylline (R03DA04); or roflumilast (R03DX07). Short-acting symptomatic treatment only was defined as short-acting $\beta 2$ agonists (SABA; R03AC02, 03 or 04) or short-acting muscarinic antagonists (SAMA; R03B01) without receiving any of the maintenance drugs during the same calendar year. Patients receiving pharmacological treatment of COPD exacerbations were defined as patients who received oral corticosteroids (OCS; H02AB) and/or antibiotics (J01).
Drugs used in maintenance and symptomatic treatment of COPD can also be used for asthma, while the drugs used for COPD exacerbation treatment (oral corticosteroids and antibiotics) can be used for a range of other conditions. From 2006, specific reimbursement codes for COPD were recorded on reimbursed prescriptions and we restricted our analyses to prescriptions with ICD-10 codes $\mathrm{J} 43$, J44, or ICPC-2 code R95, or national reimbursement code number for COPD. The use of aggregated prescription data was approved by the Norwegian Prescription Database.

\section{Statistical Analysis}

Prevalences were age-standardized according to the Norwegian population in 2012 and 5-year age groups were used.

For the spirometry parameters, lower limit of normal (LLN) was defined as the fifth percentile according to the GLI 2012 reference values. ${ }^{16}$ We applied the following thresholds indicating reduced lung function or COPD: $\mathrm{FEV}_{1}<\mathrm{LLN}$, $\mathrm{FVC}<\mathrm{LLN}, \mathrm{FEV}_{1} / \mathrm{FVC}<0.7, \mathrm{FEV}_{1} / \mathrm{FVC}<\mathrm{LLN}$, and $\mathrm{FEV}_{1}$ $/$ FVC $<$ LLN together with $\mathrm{FEV}_{1}<\mathrm{LLN}$. Since respiratory symptoms are requisite for a COPD diagnosis, we also made a category of FEV1/FVC $<$ LLN together with a positive answer to the question on dyspnea or cough (quoted above). Moderate to severe COPD was defined as FEV1/FVC $<$ LLN and FEV $1<$ LLN combined with respiratory symptoms. The prevalence of smoking and moderate to severe COPD by age at each survey was calculated in 10-year age groups.

Time trends were estimated by fitting a quasi-binomial model with a linear term in calendar year, thus allowing for variability of frailty among the age and sex groups. ${ }^{18}$ Resulting odds ratios indicate an increase in prevalence from start to the end of the studied years. When reporting the statistical significance of the odds ratios, Holm's method was used to adjust for multiple comparisons.

Because of the age standardization, we accounted for sample stratification in the analyses.

Hospital admission rates between 2010 and 2017 were calculated for men and women separately, standardized by age.

We calculated the annual prevalence of receiving any of the drugs at least once during a calendar year for the period 2010-2017. Age and sex standardized rates were computed.

The statistical analyses were performed using IBM SPSS Statistics (version 24.0; IBM Corp., Armonk, NY, USA) and by R, version 3.5.1 and 3.6.0 


\section{Results}

\section{The Tromsø Study}

\section{Participants}

The number of participants aged 40-85 years in Tromsø 5, 6 , and 7, were $7355,12,364$ and 20,842, respectively, with corresponding mean ages of $62.3,58.2$, and 57.0 years. The participation rates of those invited were $79 \%, 66 \%$ and $65 \%$, respectively. Of those invited to a second visit for extended examinations, 92.2\%, 91.8\%, and 94\% attended. Women represented $56.5 \%$ of the participants in Tromsø 5, 53.0\% in Tromsø 6, and 52.4\% in Tromsø 7. The mean Body Mass Index increased steadily from 26.8 to 27.3 between Tromsø 5 and Tromsø 7 , and the frequency of self-reported diabetes increased from $4.2 \%$ to $5.3 \%$. Reporting a previous heart attack decreased from $6.8 \%$ to $3.5 \%$.

Valid spirometry was obtained in 4902, 6294, and 7247 participants in Tromsø 5, 6, and 7, respectively, with corresponding mean ages of $66.3,63.6$ and 63.0 years.

\section{Smoking, Respiratory Symptoms and Self-Reported COPD}

The age-standardized prevalence of daily smoking dropped between Tromsø 5 and Tromsø 7 from 29.9\% and $31.4 \%$ to $14.1 \%$ and $12.8 \%$ and, in women and men, respectively (Table 1). A particularly large decrease in smoking prevalence was observed among those aged $40-49$ years, from $35.9 \%$ to $12.4 \%$, and a drop by increasing age was observed at all three surveys after 50 years of age (Figure 1). In Tromsø 5, 34.3\% had never been smoking, this percentage increased to $43.3 \%$ in Troms $\varnothing$ 7. We observed a significant decrease in the prevalence of dyspnea and cough. However, no significant change in age-standardized prevalence of self-reported COPD was observed. We found a small increase in the prevalence of self-reported asthma and/or COPD (Table 1).

\section{Lung Function}

Both $\mathrm{FEV}_{1} \%$ predicted and $\mathrm{FVC} \%$ predicted showed improved values from Tromsø 5 to Tromsø 6, and further to Tromsø 7. The mean values of $\mathrm{FEV}_{1} \%$ predicted at Tromsø 5 , 6 , and 7 were $89.8,95.5$ and 97.2 , respectively. The corresponding mean values of $\mathrm{FVC} \%$ predicted were 96.2, 100.2, and 101.7. Correspondingly, we found a decreasing prevalence of $\mathrm{FEV}_{1}<\mathrm{LLN}$ and FVC $<\mathrm{LLN}$ (Table 2, Figure 2). The mean difference between $\mathrm{FVC}$ and $\mathrm{FEV}_{6}$ increased between the three surveys and were 0.11 (uncorrected), 0.12 , and 0.15 $\mathrm{L}$ at Tromsø 5, 6, and 7, respectively.

The age-standardized prevalence of $\mathrm{FEV}_{1} / \mathrm{FVC}$ ratio $<0.7$ was stable among both women and men between Tromsø 5 and Tromsø 7 (Table 2, Figure 2), the prevalence of $\mathrm{FEV}_{1} / \mathrm{FVC}<\mathrm{LLN}$ tended to decrease among men, but not statistically significant. The prevalence of $\mathrm{FEV}_{1}$ /FVC $<$ LLN combined with respiratory symptoms (our definition of COPD) dropped significantly among men, but not among women (Table 2).

The prevalence of $\mathrm{FEV}_{1} / \mathrm{FVC}<\mathrm{LLN}$ combined with $\mathrm{FEV}_{1}<\mathrm{LLN}$ decreased from Tromsø 5 to Tromsø 7 in both sexes (Table 1, Figure 2). The results were similar when respiratory symptoms were added to the decreased

Table I Age Standardized Prevalence of Characteristics Among Participants Aged 40-84 Years in the Tromsø Study. Odds Ratios of Change in Prevalence Over 14 Years are Presented

\begin{tabular}{|c|c|c|c|c|c|c|c|c|c|c|}
\hline & \multicolumn{5}{|l|}{ Women } & \multicolumn{5}{|l|}{ Men } \\
\hline & $\begin{array}{l}200 I-2 \\
n=4 I 54\end{array}$ & $\begin{array}{l}2007-8 \\
n=6557\end{array}$ & $\begin{array}{l}2015-16 \\
n=10,929\end{array}$ & OR & $P$-value & $\begin{array}{l}2001-2 \\
n=3201\end{array}$ & $\begin{array}{l}2007-8 \\
n=5807\end{array}$ & $\begin{array}{l}2015-16 \\
n=9912\end{array}$ & OR & $P$-value \\
\hline & n $\left(\%^{a}\right)$ & n (\%) & n (\%) & & & n (\%) & n (\%) & n (\%) & & \\
\hline Daily smoking ${ }^{\mathrm{b}}$ & 1119 (29.9) & $1388(22.1)$ & $1550(14.1)$ & 0.393 & $<0.0001$ & $888(31.4)$ & $1110(19.7)$ & $1257(12.8)$ & 0.350 & $<0.0001$ \\
\hline Self-reported COPD ${ }^{c}$ & $229(4.6)$ & $307(4.5)$ & $406(4.3)$ & 0.850 & 0.9 & $153(4.0)$ & $247(4.1)$ & $337(3.5)$ & 0.892 & 1.0 \\
\hline Self-reported COPD or asthma ${ }^{c}$ & $544(11.8)$ & $876(13.3)$ & $152 \mid(\mid 4.6)$ & 1.198 & 0.03 & $353(10.1)$ & $626(10.9)$ & $1177(12.3)$ & 1.198 & 0.16 \\
\hline Body Mass Index $\geq 30^{d}$ & $853(17.8)$ & $1335(20.1)$ & $2462(22.6)$ & 1.249 & 0.1 & $557(18.6)$ & $1187(20.0)$ & $2497(25.2)$ & 1.575 & $<0.0001$ \\
\hline Dyspnea $^{e}$ & $1764(45.8)$ & $2850(48.0)$ & $4191(40.1)$ & 0.703 & 0.004 & $1295(42.4)$ & $2297(42.5)$ & $356 \mid(38.9)$ & 0.738 & 0.002 \\
\hline Cough daily in periods ${ }^{f}$ & $679(19.3)$ & $1019(16.7)$ & $1612(15.2)$ & 0.808 & 0.04 & $666(22.2)$ & $1112(20.5)$ & $1753(18.0)$ & 0.746 & 0.003 \\
\hline $\begin{array}{l}\text { Productive cough for three } \\
\text { months the two previous years }\end{array}$ & 424 (II.7) & $580(7.1)$ & $788(7.5)$ & 0.743 & 0.2 & $428(13.6)$ & $582(10.6)$ & $891(9.1)$ & 0.654 & 0.0002 \\
\hline
\end{tabular}

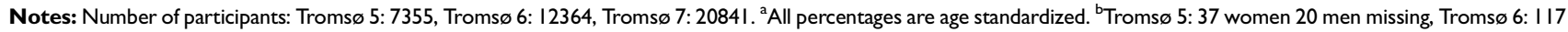
women and 68 men missing, Troms $\varnothing: 220$ women and 200 men missing. ${ }^{c}$ Troms $\varnothing$ 5: 90 women and 30 men missing, Troms $\varnothing: 123$ women and 98 men missing, Troms $\varnothing: 313$ women and 199 men missing. ${ }^{\mathrm{d}}$ Troms $\varnothing$ 5: 37 women and 29 men missing, Troms $\varnothing$ 6: I 4 women and 4 men missing, Troms $\varnothing: 33$ women and 26 men missing. ${ }^{\mathrm{e}}$ Troms $\varnothing$ 5: 608 women and 394 men missing, Tromsø 6: 635 women and 519 men missing, Tromsø 7: 217 women and 193 men missing. (Dyspnea walking fast on level ground or slight up hills). ${ }^{f}$ Troms $\varnothing$ : 589 women and 398 men missing, Tromsø 6: 503 women and 373 men missing, Tromsø 7: 212 women and 197 men missing. 


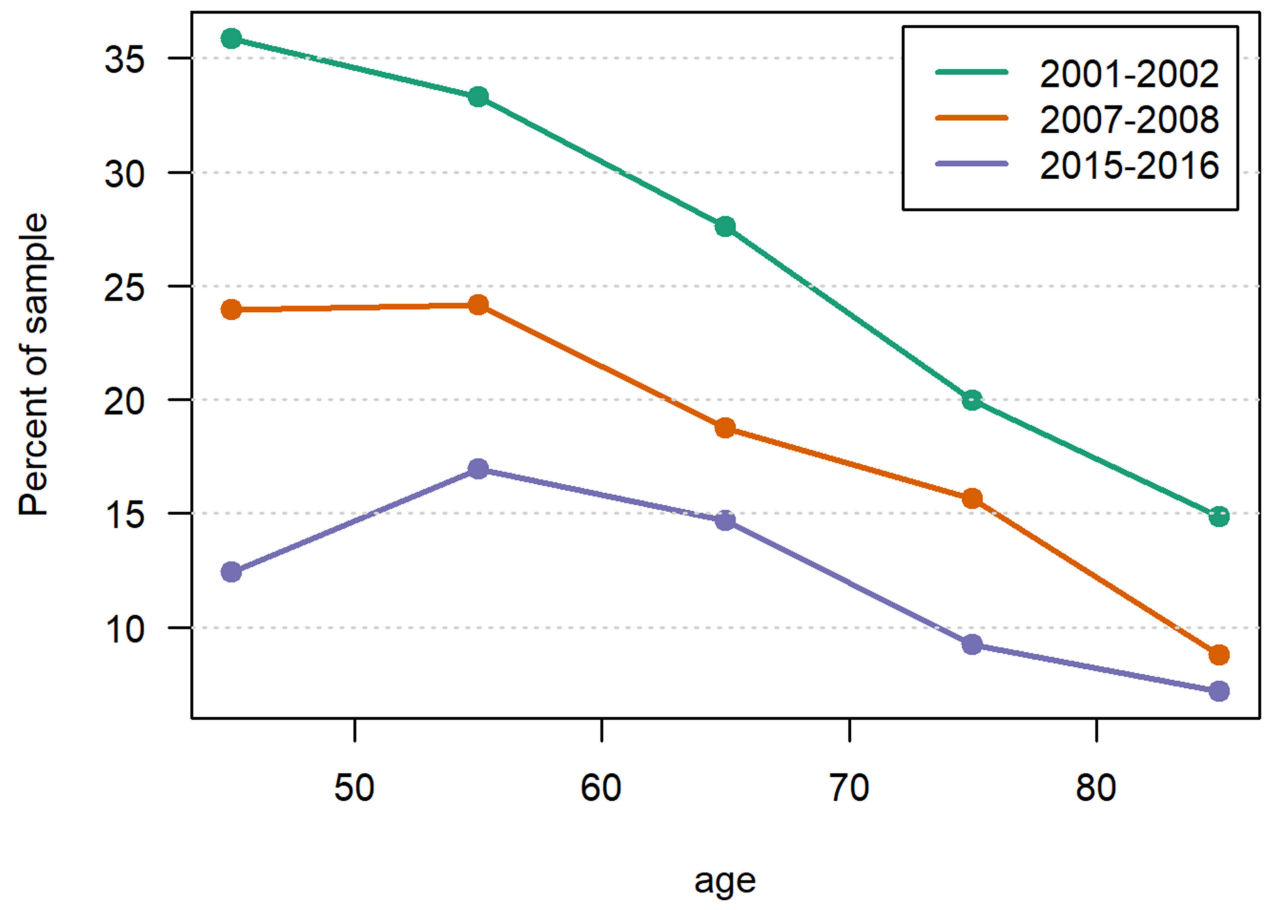

Figure I Prevalence of daily smoking by age ${ }^{\mathrm{a}}$ in three Tromsø Study surveys. ${ }^{\mathrm{b}}$

Notes: ${ }^{a} P<0.001$ in all three surveys. ${ }^{b}$ The statistical significance of change between the surveys is shown in Table I.

lung function, and the age-standardized prevalence of moderate to severe COPD dropped between 2001-2 and 2015-16 from $5.2 \%$ to $2.7 \%$ among women and from $4.6 \%$ to $3.2 \%$ among men, $P<0.001$ (Table 2 ).

The prevalence of moderate to severe COPD increased by age until the age of 80 in all three surveys. The drop in prevalence from the 5 th to the 7 th survey tended to increase with increasing age and a drop from $9.4 \%$ to $5.1 \%$ was observed for those aged $70-79$ years (Figure 3 )
The age-standardized proportion of participants with $\mathrm{SpO}_{2} \leq 95 \%$ decreased significantly between Tromsø 5 and Tromsø 7, from $8.4 \%$ to $2.6 \%$ among women and from $8.6 \%$ to $4.8 \%$ among men (Table 2 ).

\section{Smoking and COPD}

The drop in smoking between 2001 and 2015 among those with moderate to severe COPD, from $52.5 \%$ to $35.4 \%$, kept pace with those without, who had a drop from and $23.7 \%$ to

Table 2 Age Standardized Prevalence of Lung Function Characteristics Among Participants Aged 40-84 Years in the Tromsø Study. Odds Ratios of Change in Prevalence Over 14 Years are Presented

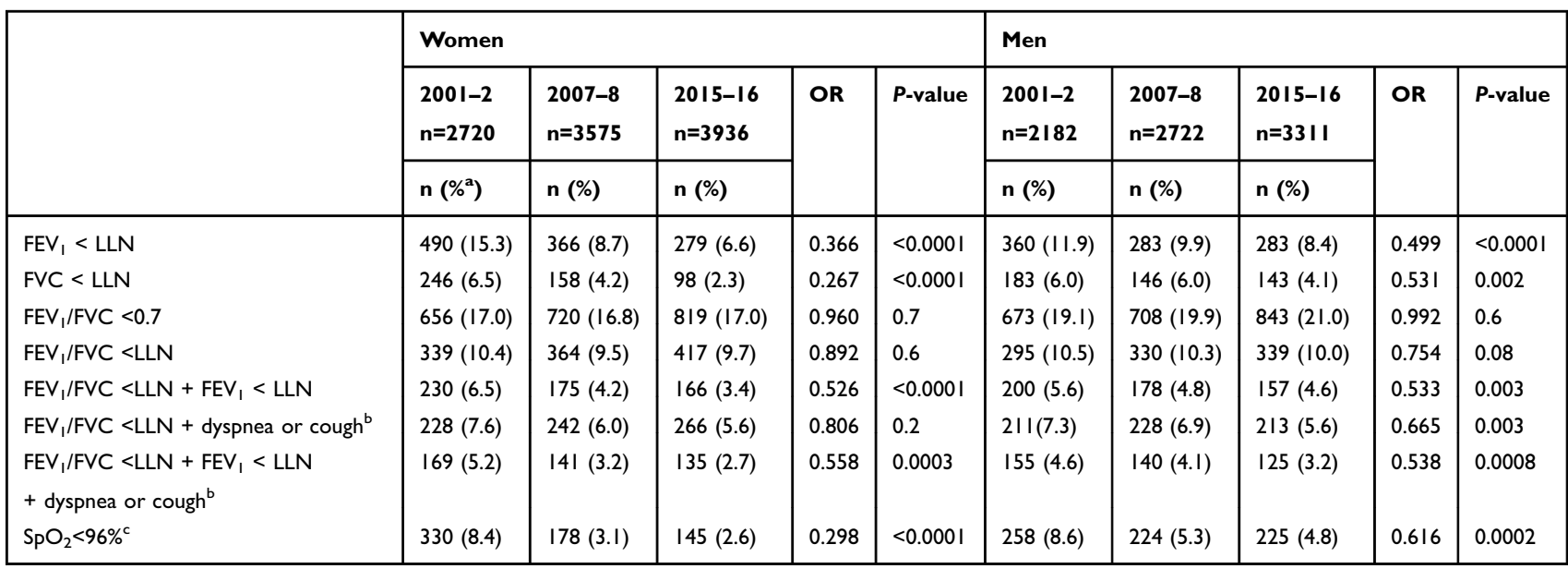

Notes: Number of participants: Troms $\varnothing$ 5: 4902, Troms $\varnothing$ 6: 6297, Tromsø 7: 7247. ${ }^{a}$ All percentages are age standardized. ${ }^{\mathrm{b}}$ Troms $\varnothing$ 5: 237 women and I39 men missing, Tromsø 6: I7I women and II6 men missing, Tromsø 7: 28 women and 44 men missing. 


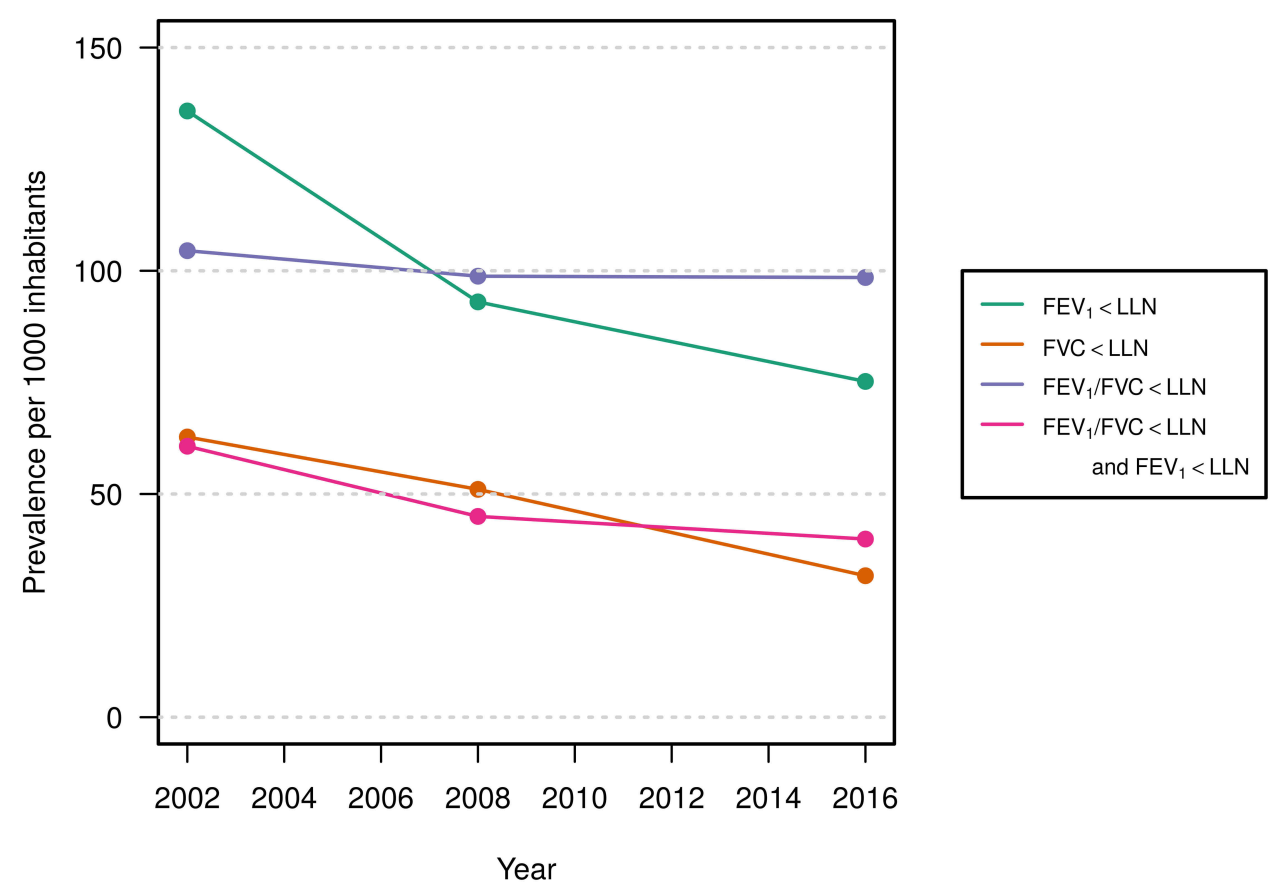

Figure 2 Age-standardized prevalence ${ }^{\text {a }}$ of spirometry results in three Tromsø Study surveys.

Notes: ${ }^{a}$ The statistical significance of the trends is shown in Table I.

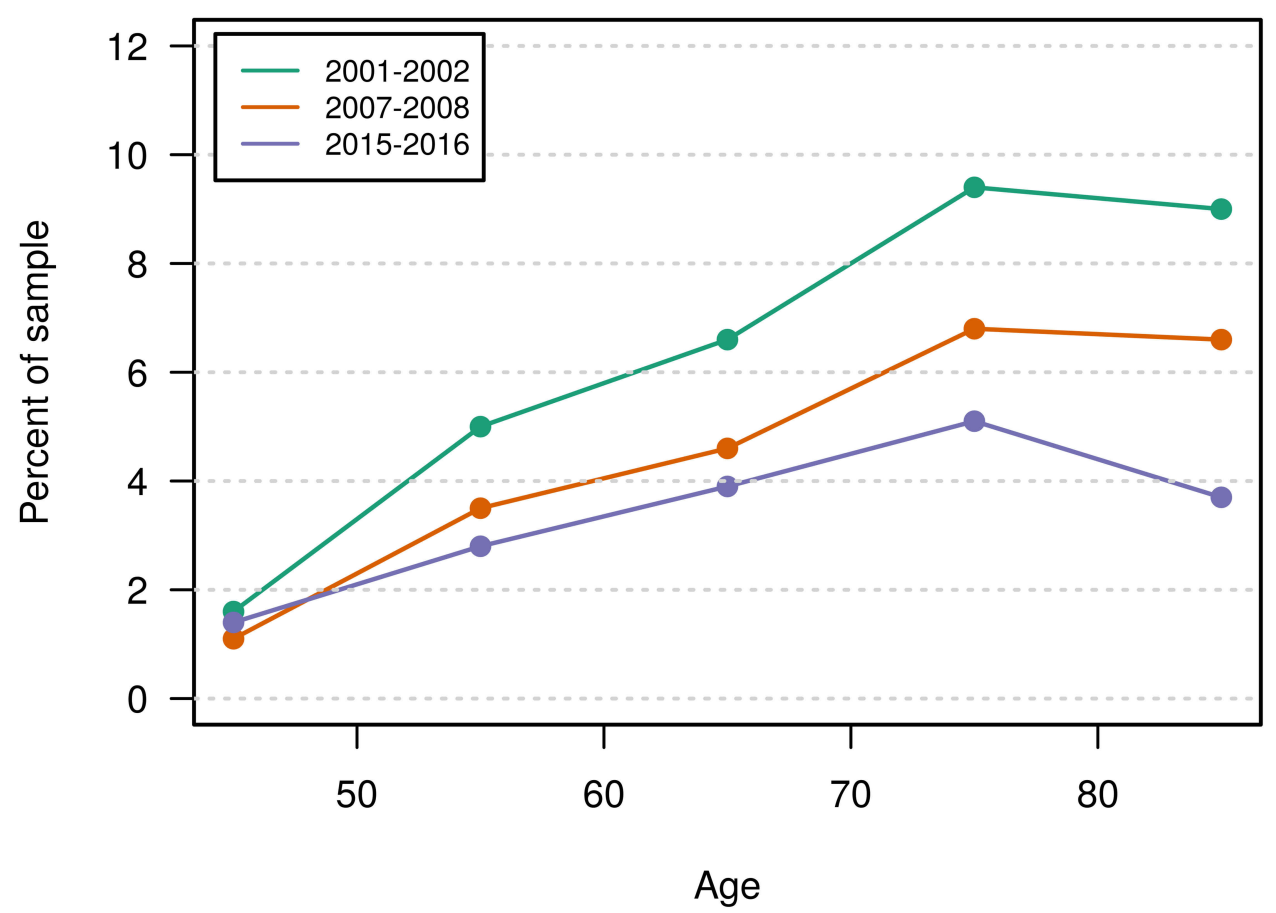

Figure 3 Prevalence of moderate to severe COPD $^{\mathrm{a}}$ by age ${ }^{\mathrm{b}}$ in three Troms $\varnothing$ Study surveys. ${ }^{\mathrm{c}}$

Notes: aModerate to severe COPD is defined as FEV $/$ FVC $<$ LLN combined with FEV $<$ LLN in subjects reporting dyspnoea or cough. ${ }^{b} P<0.00 \mathrm{I}$ in all three surveys. ${ }^{\mathrm{c}} \mathrm{The}^{\mathrm{a}}$ statistical significance of change between the surveys is shown in Table I.

$11.1 \%$. Approximately $18 \%$ of current smokers had COPD in all three surveys, the corresponding frequencies in previous smokers were $8-9 \%$. The frequency of COPD among never smokers dropped from 3.3\% to 1.8\% between 2001 and 2016 (Table 3). Analysis adjusted for age and sex, also indicated an increasing difference between current smokers and never 
Table 3 Frequency of COPD ${ }^{\mathrm{a}}$ and Moderate to Severe COPD ${ }^{\mathrm{b}}$ by Smoking Habit Between $200 \mathrm{I}$ and 2016 in the Tromsø Study

\begin{tabular}{|c|c|c|c|c|c|c|c|c|c|c|c|c|c|c|c|}
\hline & \multicolumn{5}{|c|}{$200 I-2$ (Tromsø 5) n=4492 } & \multicolumn{5}{|c|}{ 2007-8 (Tromsø 5) n=5929 } & \multicolumn{5}{|c|}{ 2015-16 (Tromsø 5) n=7142 } \\
\hline & \multirow{2}{*}{$\begin{array}{l}\text { Smoker } \\
\text { Group } \\
n\end{array}$} & \multicolumn{2}{|c|}{ COPD } & \multicolumn{2}{|c|}{$\begin{array}{l}\text { Moderate } \\
\text { to Severe } \\
\text { COPD }\end{array}$} & \multirow{2}{*}{$\begin{array}{l}\text { Smoker } \\
\text { Group } \\
\mathbf{n}\end{array}$} & \multicolumn{2}{|c|}{ COPD } & \multicolumn{2}{|c|}{$\begin{array}{l}\text { Moderate } \\
\text { to Severe } \\
\text { COPD }\end{array}$} & \multirow{2}{*}{$\begin{array}{l}\text { Smoker } \\
\text { Group } \\
n\end{array}$} & \multicolumn{2}{|c|}{ COPD } & \multicolumn{2}{|c|}{$\begin{array}{l}\text { Moderate } \\
\text { to Severe } \\
\text { COPD }\end{array}$} \\
\hline & & $\mathbf{n}$ & $(\%)$ & $\mathbf{n}$ & (\%) & & $\mathbf{n}$ & (\%) & $\mathbf{n}$ & $(\%)$ & & $\mathbf{n}$ & (\%) & $\mathbf{n}$ & (\%) \\
\hline Never smoker & 1476 & 49 & (3.3) & 34 & (2.3) & 2056 & 37 & (1.8) & 20 & $(1.0)$ & 2893 & 51 & ( 1.8$)$ & 22 & $(0.8)$ \\
\hline Previous smoker & 1872 & 167 & (8.9) & 133 & (7.1) & 2782 & 236 & (8.5) & 139 & $(5.0)$ & 3392 & 273 & $(8.0)$ & 146 & $(4.3)$ \\
\hline Current smoker & 1144 & 220 & $(19.2)$ & 154 & (13.5) & 1091 & 195 & $(17.9)$ & 124 & (II.4) & 857 & 158 & $(18.4)$ & 92 & $(10.7)$ \\
\hline
\end{tabular}

Notes: ${ }^{\mathrm{a} F E V_{1} / F V C<L L N}$ in subjects reporting dyspnea or cough. ${ }^{\mathrm{b}} \mathrm{FEV}_{1} / \mathrm{FVC}<\mathrm{LLN}$ and $\mathrm{FEV}_{1}<L L N$ in subjects reporting dyspnea or cough.

smokers in terms of COPD prevalence between 2001 and 2016. To be a current smoker predicted moderate to severe COPD, compared to never smokers, with ORs of $8.0(95 \%$ CI 5.7-11.0) in Tromsø 5 and 16.7 (95\% CI 10.4-26.8) in Tromsø 7. The corresponding ORs for previous smoking changed from 2.9 (95\% CI 2.1-4.1) to 5.6 (95\% CI 3.5-8.7).

The proportion of participants with moderate to severe COPD who reported to be diagnosed with COPD, increased from $24 \%$ in Tromsø 5 to $39 \%$ in Tromsø 6 and Tromsø 7.

\section{Hospitalization}

Age and sex standardized number of patients admitted per year between 2010 and 2017 is shown in Figure 4. For men, there was a significant and largely monotonous decrease in hospitalizations over the period, from 3.6 to 3.0 per patients per 1000 inhabitants aged $40-84$ years, resulting in an OR of 0.83 for the increased prevalence of hospitalizations over 8 years, $P<0.0001$. For women, the hospitalization rate fluctuated around 3.6 per $1000(P=0.5)$.

\section{Use of COPD Medication}

The age and sex standardized number of patients who were prescribed prednisolone or/and antibiotics for COPD exacerbations dropped between 2010 and 2017 from 6.6 to 5.8 per 1000 inhabitants, OR $0.84, P<0.0001$ (Figure 5). The corresponding number of patients on maintenance treatment for COPD increased steadily from 15.5

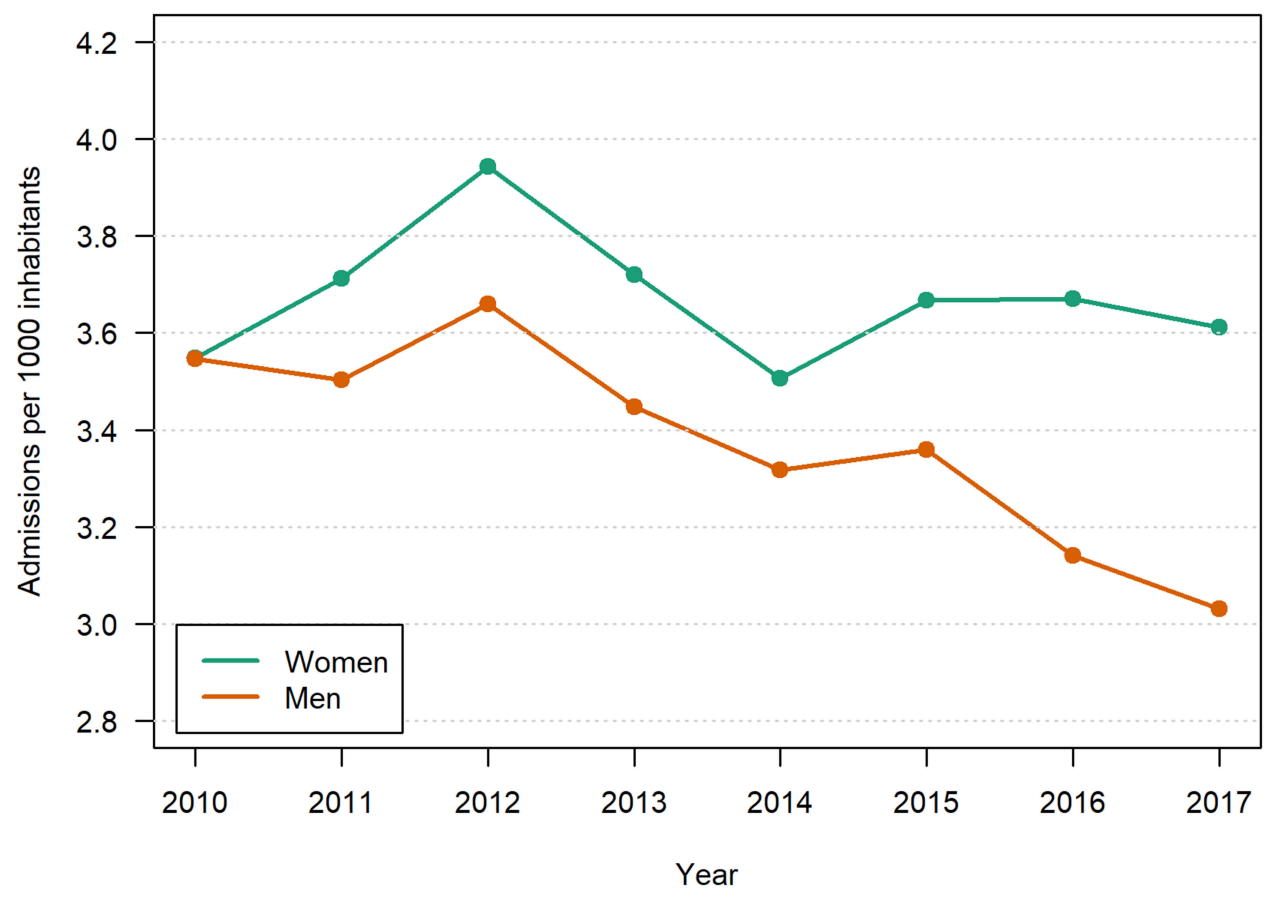

Figure 4 Number per 1000 Norwegian population aged 40-84 years hospitalized due to COPD per calendar year. Age-standardized. ${ }^{\mathrm{a}}$

Notes: ${ }^{a}$ The OddsWw Ratio of change in prevalence over 8 years was statistically significant for men, $P<0.000 \mathrm{I}$, but not for women $P=0.5$. 


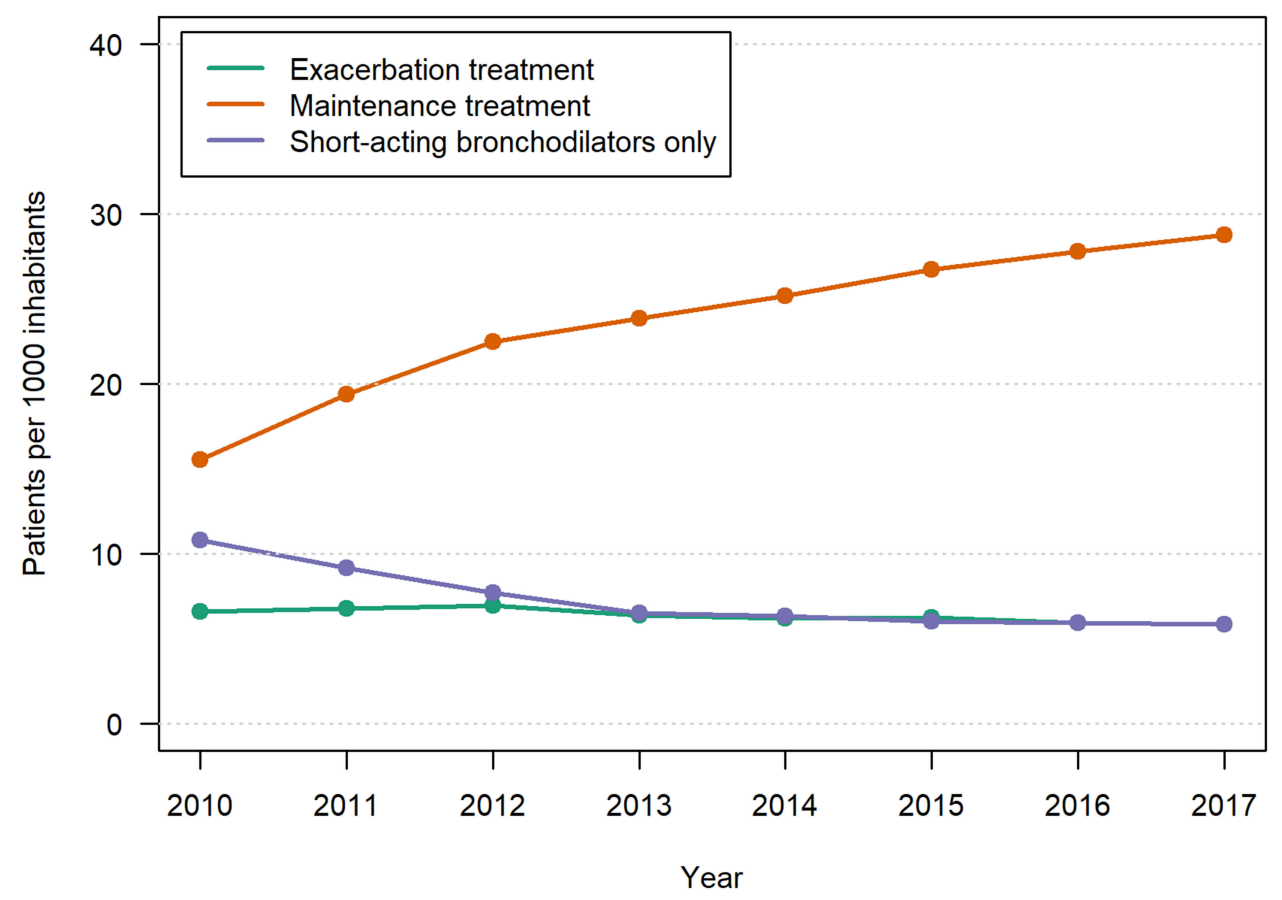

Figure 5 Number per 1000 Norwegian inhabitants aged 40-84 years who were treated with maintenance medication and systemic corticosteroids and/or antibiotics for COPD exacerbation outside hospital per calendar year. Age/sex standardized. ${ }^{a}$

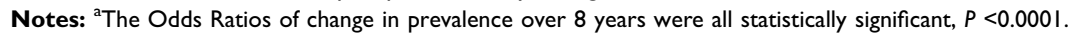

to 28.8 patients per 1000 inhabitants aged $40-84$ years, OR 1.86, $P<0.0001$. In the same period, the number of patients who were prescribed short-acting bronchodilators only as a regular treatment decreased from 9.1 to 5.8 per 1000 .

\section{Discussion}

\section{Main Findings}

By using three different and independent data sources, we found that there has been a decreasing morbidity due to COPD from 2001 to 2017. In the Tromsø population, there was a small decrease in age-standardized prevalence of COPD among men, and a pronounced decrease of moderate to severe COPD in both sexes. The age-adjusted hospitalization rate due to COPD exacerbations has decreased among Norwegian men, whereas the rate for women showed no consistent trend. We could also observe a slight decrease in the age and sex standardized prevalence of dispensed medications for COPD exacerbations, whereas the use of maintenance medication for COPD increased.

\section{Strengths and Limitations}

The Tromsø Study

The Tromsø Study has had high response rates $(65 \%$ and above), and the study has been judged to have a high external validity for the Norwegian population. ${ }^{11}$ The participation rate has varied between age groups, with the lowest rates among those younger than 50 years and those older than 80 years, and it is likely that unhealthy people have been under-represented. Due to bad health, some might have chosen to refrain from participation or not been able to attend and complete the survey. The participation rate declined somewhat from Tromsø 5 to Tromsø 7, and it is possible that unhealthy people to an increasing degree have been under-represented in the more recent surveys. Our results cannot be regarded to be valid outside Norway, at least not outside the part of the western world where we have seen a steep decrease in smoking.

The registration of self-reported COPD may be questioned. Medical doctors often misclassified COPD as asthma 2-3 decades ago, while a shift towards using the COPD label was observed between 1995 and 2005. ${ }^{19}$ Underuse of the COPD diagnosis might also have been a problem in Norway after 2006, since the reimbursement of combined long-acting bronchodilators and high dose inhaled corticosteroids became restricted a few years for COPD patients, but not when the diagnosis was asthma. We found an increased prevalence of self-reported COPD and/ or asthma. A wave of more frequent use of asthma diagnosis in children and young adults starting at the end of the 
previous century has probably with increasing strength reached the age group we have studied after year $2000 .{ }^{20}$

The spirometers used in Tromsø 5 were different from that used in Tromsø 6 and 7. Due to too low measurements with the Vmax Legacy, the results in Tromsø 5 had to be adjusted. However, the adjustment was based on measurements in 48 subjects only. ${ }^{15}$ The adjustment might have been too confined and contributed to the much lower $\mathrm{FEV}_{1}$ and FVC values in Tromsø 5 than in the two later surveys. Without adjustment the prevalence of $\mathrm{FEV}_{1}<\mathrm{LLN}$ and FVC $<$ LLN would be higher and that of $\mathrm{FEV}_{1} / \mathrm{FVC}$ $<$ LLN be lower, due to the higher correction factor for $\mathrm{FVC}$ than for $\mathrm{FEV}_{1}$.

In spite of the increase in $\mathrm{FEV}_{1} \%$ predicted between Tromsø 5 and 7, neither $\mathrm{FEV}_{1} / \mathrm{FVC}<0.7$ nor $\mathrm{FEV}_{1} / \mathrm{FVC}$ $<$ LLN became significantly less prevalent. Reduced $\mathrm{FEV}_{1}$ /FVC is an early sign of COPD, and since it usually occurs earlier in life than reduced $\mathrm{FEV}_{1}$, a longer observation time than 15 years may be needed for finding a significant decrease in prevalence. The considerable increase in mean $\mathrm{FVC} \%$ predicted might have contributed. The participants were strongly encouraged to expire as long as possible, and perhaps more strongly than in surveys on which the GLI 2012 reference relies. We found a mean $\mathrm{FVC} \%$ predicted above $100 \%$ in our general population, which, in contrast to the reference populations, include smokers and subjects with heart and lung diseases. In line with this, the Norwegian validation study of GLI 2012 also found the GLI reference values to underestimate $\mathrm{FVC}$, but within levels acceptable for use of GLI 2012 in Norway. ${ }^{16}$ Increased FVC values due to longer expirations might have been counteracted by the increased prevalence of obesity. Variation in how the spirometry is performed may make $\mathrm{FEV}_{1} \%$ predicted a more valid measure of airflow limitation change than $\mathrm{FEV}_{1} / \mathrm{FVC}$.

The prevalence of $\mathrm{FEV}_{1} / \mathrm{FVC}<0.7$ was almost twice as high as the prevalence of $\mathrm{FEV}_{1} / \mathrm{FVC}<\mathrm{LLN}$. We found a further decrease in the prevalence of COPD when respiratory symptoms were added to the diagnostic criteria. This is in line with GOLD's recommendations, ${ }^{12}$ but seldom applied in epidemiological surveys.

The inclusion of pulse oximetry is a strength of the study; a decreasing prevalence of oxygen saturation $\leq 95 \%$ supports our finding of improved lung health. Likewise, finding a decreased prevalence of respiratory symptoms gives support to the main results of the study.
Impact of other factors that could lead to fewer exacerbations, like vaccination against influenza ${ }^{21}$ and participation in rehabilitation programs ${ }^{22}$ could not be elucidated.

\section{The Norwegian Patient Registry}

Our study is based on complete data from all acute care Norwegian hospitals. It was possible to track patients during transfers at different hospitals. To the best of our knowledge, no similar study has been performed. NPR, the data source, has been validated for several disease categories with respect to identification of cases based on diagnoses and/or procedures and found to have a very high degree of completeness, compared to Norwegian national medical quality registries. ${ }^{23,24}$

It is conceivable that the threshold for hospital admission for COPD exacerbations has changed over time. However, an analysis of readmissions (data not shown) indicates that this has not been the case.

\section{The Norwegian Prescription Database}

The coding of prescriptions which identifies the medication prescribed for COPD makes the database very suitable for our purpose. There is a limitation concerning the use of systemic corticosteroids, which are dispensed in packages enough for more than one exacerbation. The number of patients per year using such medication for COPD exacerbations may thus be underestimated. However, this has probably not influenced the trend in dispensed drugs over time.

\section{Comparisons with Previous Research}

An even larger drop in age and sex-adjusted prevalence of $\mathrm{FEV}_{1} / \mathrm{FVC}<\mathrm{LLN}$ combined with $\mathrm{FEV}_{1}<\mathrm{LLN}$ was found in Sweden between 1994 and 2009, from $8.1 \%$ to $3.1 \%$, ${ }^{6}$ The prevalence in Tromsø had not reached the same level in 2015 (symptoms disregarded), 4.6\% in men and 3.4\% in women. The association between current smoking and moderate to severe COPD, was similarly strong over time in the Swedish study, current smoking predicted moderate to severe COPD with an OR of 7.6 and 11.9 in 1994 and 2009 , respectively. In a study from another part of Norway, a drop in the prevalence of $\mathrm{FEV}_{1} / \mathrm{FVC}<\mathrm{LLN}$ between 1995-7 and 2006-8 from $13.0 \%$ to $7.7 \%$ was found among men, but the drop among women, from $8.8 \%$ to $6.9 \%$, was not statistically significant. ${ }^{7}$ A similar tendency was found in our study, but the drop in the prevalence of $\mathrm{FEV}_{1} / \mathrm{FVC}<\mathrm{LLN}$ between 2001 and 2016 did not reach statistical significance. Neither did we find a drop in the 
prevalence of $\mathrm{FEV}_{1} / \mathrm{FVC}<0.7$, which in 2015-16 was $17.1 \%$ in women and $21.1 \%$ in men. This prevalence was higher than the corresponding prevalence of $9.9 \%$ and $15.7 \%$ reported in a recent global systematic review. ${ }^{25}$ In this review, COPD was defined by post-bronchodilator $\mathrm{FEV}_{1} / \mathrm{FVC}<0.7$. We used pre-bronchodilator spirometry, and that might partly explain the higher prevalence. ${ }^{26}$ The effort to make our study subjects expire as long as possible, also beyond $6 \mathrm{~s}$, might also have contributed.

We found a considerable drop in the prevalence of decreased $\mathrm{SpO}_{2}$ between 2001 and 2016 (Table 1). The prevalence in 2001 (8.4\% and $8.6 \%$ in women and men, respectively) might seem high, but the prevalence of $\mathrm{SpO} 2$ $\leq 95 \%$ was $22 \%$ in a study from primary care of patients with asthma and COPD. ${ }^{27}$ Decreasing the incidence of coronary heart disease in Troms $\varnothing^{28}$ can have contributed to improved oxygen saturation. ${ }^{17}$

Increased use of maintenance treatment with LABA has been found between 2002 and 2009 in a European comparative study. ${ }^{29}$ In Denmark, a steady increase in prevalent users of maintenance treatment for COPD between 2000 and 2016, a 39\% increase in total, was found by Reilev and coworkers. ${ }^{30}$

\section{Interpretation of the Results}

The beneficial effect of smoking cessation for the clinical course of COPD has been shown in several studies, ${ }^{3,31}$ and it seems reasonable to argue that the steep drop in current smoking in Norway has led to healthier lungs. We have also seen an increased awareness of COPD as a severe, but preventable disease, well represented by the GOLD initiative. Medical treatment of COPD patients at all stages of the disease has improved. The frequency of underdiagnoses seems to be decreasing; increased use of spirometry in primary care ${ }^{19}$ might partly explain why $39 \%$ of participants with moderate to severe COPD reported a COPD diagnosis in 2007 and 2015 compared to only $24 \%$ in 2001 . To be diagnosed with COPD can not only result in a higher rate of smoking cessation, ${ }^{32}$ but also to initiation of medical treatment. Maintenance treatment with long-acting bronchodilators can in some COPD patient reduce symptoms and lead to improvement of lung function, ${ }^{33}$ and the number of COPD patients fulfilling the criteria of moderate to severe COPD could be somewhat reduced. Maintenance treatment can also to some degree prevent severe exacerbations, ${ }^{33}$ and thus contribute to the decreased hospitalization rate observed in our study. However, the increased awareness of COPD as a severe disease might have decreased the threshold for hospital admissions.

We found that the difference in risk of COPD between smokers and never smokers has increased. Fresher air, both at work and at home, might have been particularly beneficial for non-smokers. A strong link between COPD and socioeconomic status might also have played a role. ${ }^{34}$

\section{Implications for Clinical Practice}

In spite of increased use of spirometry in primary care, COPD is still an underdiagnosed disease. ${ }^{35}$ Although availability of spirometers, the application of the instrument varies greatly between practices. ${ }^{34}$ To promote a further drop in smoking prevalence among subjects with COPD, improved identification of the disease should be given high priority. This might also lead to better medical treatment.

\section{Conclusion}

We have documented a decreased COPD morbidity between 2001 and 2017. The decrease is, so far, not very large, but the drop in smoking prevalence, particularly among those younger than 50 years, gives promise of a further substantial decrease in the coming decades.

\section{Acknowledgments}

Data from the Norwegian Patient Registry have been used in this publication. The interpretation and reporting of these data are the sole responsibility of the authors, and no endorsement by the Norwegian Patient Registry is intended nor should be inferred.

\section{Author Contributions}

The study was conceived by HM in dialog with the whole group of authors. Data were provided by the Tromsø Study, the Norwegian Patient Registry, and the Norwegian Prescription Database. Analysis was performed by HM, IA, and JH. All authors made substantial contributions to conception and design, interpretation of data, and took part in drafting the article or revising it critically for important intellectual content; gave final approval of the version to be published; and agree to be accountable for all aspects of the work.

\section{Disclosure}

Mr Øystein Karlstad reports funding from Leo Pharma, outside the submitted work. The authors report no other conflicts of interest in this work. 


\section{References}

1. Wipfli H, Samet JM. One hundred years in the making: the global tobacco epidemic. Annu Rev Public Health. 2016;37:149-166. doi:10.1146/annurev-publhealth-032315-021850

2. Statistics Norway ; 2019. Tobacco, alcohol and other drugs. Available from: www.ssb.no/en/statbank/table/07662. Accessed February 7, 2020.

3. Kohansal R, Martinez-Camblor P, Agusti A, Buist AS, Mannino DM, Soriano JB. The natural history of chronic airflow obstruction revisited: an analysis of the Framingham offspring cohort. Am J Respir Crit Care Med. 2009;180(1):3-10. doi:10.1164/rccm.200901-0047OC

4. Soriano JB, Ancochea J, Miravitlles M, et al. Recent trends in COPD prevalence in Spain: a repeated cross-sectional survey 1997-2007. Eur Respir J. 2010;36(4):758-765. doi:10.1183/09031936.00138409

5. Bischoff EW, Schermer TR, Bor H, Brown P, van WC, van den Bosch WJ. Trends in COPD prevalence and exacerbation rates in Dutch primary care. Br J Gen Pract. 2009;59(569):927-933. doi:10.3399/bjgp09X473079

6. Backman H, Eriksson B, Ronmark E, et al. Decreased prevalence of moderate to severe COPD over 15 years in northern Sweden. Respir Med. 2016;114:103-110. doi:10.1016/j.rmed.2016.03.013

7. Bhatta L, Leivseth L, Mai XM, et al. Prevalence and trend of COPD from 1995-1997 to 2006-2008: the HUNT study, Norway. Respir Med. 2018;138:50-56. doi:10.1016/j.rmed.2018.03.020

8. Reitsma MB, Fullman N, Ng M. Smoking prevalence and attributable disease burden in 195 countries and territories, 1990-2015: a systematic analysis from the Global Burden of Disease Study 2015. Lancet 2017;389(10082):1885-1906. doi:10.1016/S0140-6736(17)30819-X

9. Vieira R, Fonseca JA, Lopes F, Freitas A. Trends in hospital admissions for obstructive lung disease from 2000 to 2010 in Portugal. Respir Med. 2016;116:63-69. doi:10.1016/j.rmed.2016.05.018

10. Liu H, Wang N, Chen W, et al. Hospitalization Trends in Adult Patients with COPD and other respiratory diseases in Northeast China from 2005 to 2015. Biomed Res Int. 2018;2018:1060497.

11. Jacobsen BK, Eggen AE, Mathiesen EB, Wilsgaard T, Njolstad I. Cohort profile: the Tromso Study. Int J Epidemiol. 2012;41 (4):961-967. doi:10.1093/ije/dyr049

12. Mirza S, Clay RD, Koslow MA, Scanlon PD. COPD guidelines: a Review of the 2018 GOLD report. Mayo Clin Proc. 2018;93 (10):1488-1502. doi:10.1016/j.mayocp.2018.05.026

13. Miller MR, Hankinson J, Brusasco V, et al. Standardisation of spirometry. Eur Respir J. 2005;26(2):319-338. doi:10.1183/ 09031936.05.00034805

14. [No authors listed]. Standardization of Spirometry, 1994 Update American Thoracic Society. Am J Respir Crit Care Med. 1995;152 (3):1107-1136. doi:10.1164/ajrccm.152.3.7663792

15. Vold ML, Aasebo U, Melbye H. Low FEV1, smoking history, and obesity are factors associated with oxygen saturation decrease in an adult population cohort. Int $J$ Chron Obstruct Pulmon Dis. 2014;9:1225-1233. doi:10.2147/COPD.S69438

16. Langhammer A, Johannessen A, Holmen TL, et al. Global Lung Function Initiative 2012 reference equations for spirometry in the Norwegian population. Eur Respir J. 2016;48(6):1602-1611. doi:10.1183/13993003.00443-2016

17. Vold ML, Aasebo U, Hjalmarsen A, Melbye H. Predictors of oxygen saturation $\leq 95 \%$ in a cross-sectional population based survey. Respir Med. 2012;106(11):1551-1558. doi:10.1016/j.rmed.2012.06.016

18. McCullagh P. Generalized Linear Models. 2nd ed. Chapman \& Hall; 1989.

19. Haugan T, Bakken IJ, Storro O, Oien T, Langhammer A. Utvikliing i diagnostisering og helsetjenesteforbruk ved obstruktiv lungesykdom [Utilization of diagnostic tools and health care services for obstructive lung disease]. Tidsskr nor Laegeforen. 2008;128(21):2431-2434.
20. Ryan-Ibarra S, Milet M, Lutzker L, Rodriguez D, Induni M, Kreutzer R. Age, period, and cohort effects in adult lifetime asthma prevalence in California: an application of hierarchical age-periodcohort analysis. Ann Epidemiol. 2016;26(2):87-92. doi:10.1016/j. annepidem.2015.12.002

21. Mulpuru S, Li L, Ye L, et al. Effectiveness of influenza vaccination on hospitalizations and risk factors for severe outcomes in hospitalized patients with COPD. Chest. 2019;155(1):69-78. doi:10.1016/j. chest.2018.10.044

22. Puhan MA, Gimeno-Santos E, Cates CJ, Troosters T. Pulmonary rehabilitation following exacerbations of chronic obstructive pulmonary disease. Cochrane Database Syst Rev. 2016;12:CD005305. doi:10.1002/14651858.CD003091.pub4

23. Oie LR, Madsbu MA, Giannadakis C, et al. Validation of intracranial hemorrhage in the Norwegian patient registry. Brain Behav. 2018;8 (2):e00900. doi:10.1002/brb3.2018.8.issue-2

24. Varmdal T, Bakken IJ, Janszky I, et al. Comparison of the validity of stroke diagnoses in a medical quality register and an administrative health register. Scand J Public Health. 2016;44(2):143-149. doi: $10.1177 / 1403494815621641$

25. Varmaghani M, Dehghani M, Heidari E, Sharifi F, Moghaddam SS, Farzadfar F. Global prevalence of chronic obstructive pulmonary disease: systematic review and meta-analysis. East Mediterr Health J. 2019;25(1):47-57. doi:10.26719/emhj.18.014

26. Johannessen A, Omenaas ER, Bakke PS, Gulsvik A. Implications of reversibility testing on prevalence and risk factors for chronic obstructive pulmonary disease: a community study. Thorax. 2005;60(10):842-847. doi:10.1136/thx.2005.043943

27. Dalbak LG, Straand J, Melbye H. Should pulse oximetry be included in GPs' assessment of patients with obstructive lung disease? Scand J Prim Health Care. 2015;33(4):305-310. doi:10.3109/028134 32.2015.1117283

28. Mannsverk J, Wilsgaard T, Mathiesen EB, et al. Trends in modifiable risk factors are associated with declining incidence of hospitalized and nonhospitalized acute coronary heart disease in a population. Circulation. 2016;133(1):74-81. doi:10.1161/CIRCULATIONAHA.115.016960

29. Rottenkolber M, Voogd E, van DL, et al. Time trends of period prevalence rates of patients with inhaled long-acting beta-2agonists-containing prescriptions: a European comparative database study. PLoS One. 2015;10(2):e0117628. doi:10.1371/journal.pone. 0117628

30. Reilev M, Pottegard A, Davidsen JR, et al. Seventeen-year nationwide trends in use of long-acting bronchodilators and inhaled corticosteroids among adults - a danish drug utilization study. Basic Clin Pharmacol Toxicol. 2018;123(1):58-64. doi:10.1111/bcpt.2018.123. issue-1

31. Anthonisen NR, Connett JE, Murray RP. Smoking and lung function of Lung Health Study participants after 11 years. Am J Respir Crit Care Med. 2002;166(5):675-679. doi:10.1164/rccm.2112096

32. Danielsen SE, Lochen ML, Medbo A, Vold ML, Melbye H. A new diagnosis of asthma or COPD is linked to smoking cessation - the Tromso study. Int J Chron Obstruct Pulmon Dis. 2016;11:1453-1458. doi:10.2147/COPD.S108046

33. Horita N, Goto A, Shibata Y, et al. Long-acting muscarinic antagonist (LAMA) plus long-acting beta-agonist (LABA) versus LABA plus inhaled corticosteroid (ICS) for stable chronic obstructive pulmonary disease (COPD). Cochrane Database Syst Rev. 2017;2:CD012066.

34. Hetlevik O, Melbye H, Gjesdal S. GP utilisation by education level among adults with COPD or asthma: a cross-sectional register-based study. NPJ Prim Care Respir Med. 2016;26:16027. doi:10.1038/ npjpcrm.2016.27

35. Ho T, Cusack RP, Chaudhary N, Satia I, Kurmi OP. Under- and over-diagnosis of COPD: a global perspective. Breathe (Sheff). 2019;15(1):24-35. doi:10.1183/20734735.0346-2018 


\section{Publish your work in this journal}

The International Journal of COPD is an international, peer-reviewed journal of therapeutics and pharmacology focusing on concise rapid reporting of clinical studies and reviews in COPD. Special focus is given to the pathophysiological processes underlying the disease, intervention programs, patient focused education, and self management protocols. This journal is indexed on PubMed Central, MedLine and CAS. The manuscript management system is completely online and includes a very quick and fair peer-review system, which is all easy to use. Visit http://www.dovepress.com/testimonials.php to read real quotes from published authors.

Submit your manuscript here: https://www.dovepress.com/international-journal-of-chronic-obstructive-pulmonary-disease-journal 